\title{
High-density lipoprotein (HDL) particle size and concentration changes in septic shock patients
}

\author{
Sébastien Tanaka ${ }^{1,2}$, Dévy Diallo3 ${ }^{3}$, Sandrine Delbosc ${ }^{3}$, Claire Genève $^{2}$, Nathalie Zappella², Jennyfer Yong-Sang ${ }^{1}$ \\ Jessica Patche ${ }^{1}$, Anatole Harrois ${ }^{4,5}$, Sophie Hamada ${ }^{4}$, Erick Denamur ${ }^{6}$, Philippe Montravers ${ }^{2,7}$, \\ Jacques Duranteau ${ }^{4,5}$ and Olivier Meilhac ${ }^{1,8,9^{*}}$ (D)
}

\begin{abstract}
Background: Sepsis is associated with systemic inflammation that may impact lipoprotein function. In particular, high-density lipoproteins (HDLs) that display pleiotropic protective roles may be dysfunctional in septic conditions. The aim of this study was to evaluate the HDL profile and the inflammatory context in septic shock patients admitted to our intensive care unit (ICU).

Methods: In this study, 20 septic shock patients and 20 controls (ICU patients without septic shock) were included. Plasma samples were collected on days 1,2 and 7. Total cholesterol and lipoprotein concentrations were determined. HDL profiles were obtained using the Lipoprint ${ }^{\circledR}$ System (non-denaturing electrophoresis). Quantification of pro-inflammatory cytokines (interleukin 1b, 6 and 8), cell-free DNA and lipopolysaccharide-binding protein was also performed.

Results: HDL concentration was statistically lower in septic shock patients than in controls. At days 1 and 2, septic patients had significantly more large-sized HDL than control patients. Patients recovered a normal lipid profile at day 7.

Conclusions: Our results emphasize that HDL levels are dramatically decreased in the acute phase of septic shock and that there is a shift toward large HDL particles, which may reflect a major dysfunction of these lipoproteins. Further mechanistic studies are required to explore this shift observed during sepsis.
\end{abstract}

Keywords: Inflammation, Intensive care unit, Lipoprint, Lipid profile, Sepsis, High-density lipoproteins, Size

\section{Background}

Sepsis is still the major cause of mortality in critically ill patients [1-3]. Inflammation associated with sepsis is characterized by increased levels of circulating biomarkers including chemokines, cytokines, coagulation factors, etc., that reflect and participate in organ dysfunction $[4,5]$. Previous studies have suggested that during sepsis, multiple organ dysfunctions are consecutive to

\footnotetext{
${ }^{*}$ Correspondence: olivier.meilhac@inserm.fr

${ }^{9}$ INSERM U1 188 Diabète athérothrombose Thérapies Réunion Océan Indien (DéTROI), Université de La Réunion au CYROI, 2, Rue Maxime Rivière, 97490 Sainte Clotilde, La Réunion, France

Full list of author information is available at the end of the article
}

endothelial alterations leading to platelet and leukocyte activation and/or coagulation pathway perturbations $[6,7]$. High-density lipoproteins (HDLs), in addition to their function of reverse cholesterol transport $[8,9]$, display pleiotropic properties such as the induction of nitric oxide (NO) production by endothelial cells [10], inhibition of platelet activation [11] or the capacity to neutralize lipopolysaccharides (LPS) $[12,13]$. HDLs have also been reported to modulate neutrophil activation as the endothelial response to pro-inflammatory cytokines such as TNF-alpha [14]. HDLs may bind to enzymes such as paraoxonase (PON1) or platelet-activating factor acetylhydrolase (PAF-AH) which display antioxidant and 
endothelium protective properties [13]. Both PON1 and PAF-AH have been shown to limit lipid oxidation [13, $15]$.

In the cardiovascular field, both HDL cholesterol (HDL-C) concentration and HDL particle size were independently associated with cardiovascular risk [16]. In particular, large HDL particles appear to be protective in coronary artery disease $[17,18]$. To our knowledge, HDL size has never been explored in septic patients.

Clinical studies have emphasized that HDL-C rapidly decreased during sepsis $[19,20]$ and that low levels of HDL-C are associated with increased mortality and adverse clinical outcomes during sepsis [21-23]. In a previous study, we have compared HDL profiles between septic and trauma patients [20]. Although inflammation was exacerbated in these two entities, HDL-C levels were low in septic patients, whereas their concentration was not altered in cases of trauma. The anti-inflammatory properties of HDLs and their capacity to limit endothelial activation are thus decreased in septic conditions. We hypothesized that in addition to reduced HDL concentration, their size may be modified in septic conditions.

\section{Materials and methods}

The aim of the present study was to characterize HDL particles concentration and size in septic shock patients hospitalized in our intensive care unit.

\section{Patients}

The study was performed in a surgical intensive care unit (ICU) of a 1000-bed tertiary referral university hospital. All adult patients admitted to the ICU were enrolled in this prospective observational study when they fulfilled the criteria for septic shock according to the Surviving Sepsis Campaign International Guidelines. This study was approved by our local ethics committee (Comité de Protection des Personnes de l'Université Paris VII no SC 13-026), which waived the need for written informed consent because of the observational nature of the study. During this period, all non-septic patients hospitalized in the ICU were prospectively included in a control group.

No differences for age or sex were observed between the two groups. The main ICU admission diagnoses were severe trauma, acute severe bleeding, acute brain injury or intracerebral hemorrhage. Immuno-compromised patients (AIDS, neutropenia of $<1000$ cells $/ \mathrm{mL}$ or transplant surgery) and patients with liver cirrhosis were excluded from the study.

According to our local procedures, early enteral feeding was always preferred. If the enteral route was not possible, a parenteral nutrition was administrated and changed for enteral nutrition as soon as possible. Some patients received both enteral and parenteral nutrition.

\section{Data collection}

Demographic data were collected at the patient's admission (age, sex, SAPSII, SOFA score, weight, previous medical history and especially dyslipidemia and ICU admission diagnosis). Hyperlipidemia is defined as an elevation of the fasting total cholesterol concentration, which may or may not be associated with increased triglyceride concentration. Statin treatment is recommended according to international guidelines [24]. Blood was sampled at days 1, 2 and 7 after admission for determination of total cholesterol, HDL-C, triglycerides, LDL cholesterol (LDL-C), protein concentrations and leukocyte count.

\section{Determination of HDL profiles by the Quantimetrix Lipoprint ${ }^{\circledR}$ HDL system}

HDL size profiles were obtained using Lipoprint technology (Eurobio, France). The separation of HDL subfractions in plasma was achieved using this non-denaturing electrophoresis system. Precast high-resolution $8.5 \%$ polyacrylamide gel tubes were used. Briefly, $40 \mu \mathrm{l}$ of sample was mixed with $300 \mu \mathrm{l}$ of loading gel. This mixture was added to the top of the gel tubes, and a photo polymerization was carried out at room temperature for $30 \mathrm{~min}$. Then, the gel tubes containing samples were electrophoresed for 54 min with $3 \mathrm{~mA} /$ gel. When the electrophoresis was finished, the gel tubes were left to rest for $30 \mathrm{~min}$ before scanning. This incubation at ambient temperature was added to the protocol to increase the uniformity of the bands. After scanning with a ScanMaker 8700 digital scanner (Mikrotek Co, USA), analysis with lipoware software was performed and the different bands (fractions of lipoproteins) were identified by their mobility (Rf) using a starting reference point and a leading point.

\section{Apolipoprotein A-I ELISA}

The plasma apo A-I concentration was determined using a commercial kit (Mabtech, Sweden). The whole procedure was performed at room temperature. A high protein-binding ELISA plate was coated overnight with $\mathrm{mAb}$ HDL diluted to $2 \mu \mathrm{g} / \mathrm{ml}$ in PBS, $\mathrm{pH} 7.4(100 \mu \mathrm{l}$ in each well). The plate was washed twice with PBS, and blocked by adding $150 \mu \mathrm{l}$ (by well) of PBS containing $0.05 \%$ Tween 20 and $0.1 \%$ BSA (incubation buffer) and leaving for $1 \mathrm{~h}$. Five washes were then performed with PBS containing $0.05 \%$ Tween $20.100 \mu \mathrm{l}$ per well of diluted patient's plasma $(1: 100,000)$ and standards (dilution range from 50 to $0 \mathrm{ng} / \mathrm{ml}$ ) was incubated for $2 \mathrm{~h}$. A washing step similar to the second one was then performed. Then, $100 \mu \mathrm{l} /$ well of $\mathrm{mAb}$ HDL linked to biotin at $0.5 \mu \mathrm{l} / \mathrm{ml}$ was added and incubated for $1 \mathrm{~h}$ after which another washing step was 
performed. Streptavidin-HRP diluted at 1:1000 in incubation buffer was then added $(100 \mu \mathrm{l} /$ well). After $1 \mathrm{~h}$ of incubation followed by fives washes, $100 \mu \mathrm{l}$ of substrate were added to each well, and after $5 \mathrm{~min}$, the colorimetric reaction was stopped by adding $50 \mu \mathrm{l}$ of $\mathrm{H} 2 \mathrm{SO} 41 \mathrm{M}$. The optical density was measured at $405 \mathrm{~nm}$.

\section{LPS-binding protein (LBP) ELISA}

LBP concentrations were measured using a commercial ELISA kit (Cell Sciences Inc), samples were diluted 1:1000, and the assay was carried out according to the manufacturer's protocol, with a standard curve ranging from 5 to $50 \mu \mathrm{g} / \mathrm{mL}$.

\section{Cell-free DNA quantification}

Determination of the quantity of free DNA in plasma of patients was achieved using Quantit ${ }^{\mathrm{TM}}$ Picogreen dsDNA Reagent (Life technologies, France), as previously described [25].

\section{Cytokines ELISA tests}

All plasma samples were diluted fourfold with Bio-Plex sample diluents. Samples were analyzed for three different cytokines (IL-1b, IL-6 and IL-8) by a Bio-Plex Pro $^{\text {TM }}$ Human Cytokine Assay (Bio-Rad Laboratories,
Inc., Hercules, CA, USA), according to the supplier's instructions.

\section{Statistical analysis}

Continuous variables are expressed as median (interquartile range), and categorical variables are expressed as frequencies (percentages). Categorical variables were compared by the Chi-Square test or Fisher's exact test when expected cell frequency was $<5$. Continuous variables were compared by the Mann-Whitney U test. The Spearman rank coefficient was calculated for evaluating correlations. For all tests, $P<0.05$ was considered significant. Graphpad Prism 4.0 (Graphpad Software, La Jolla, CA, USA) was used for statistical analysis.

\section{Results}

Patients

Twenty septic and 20 control patients were consecutively included in our study. The baseline characteristics of the subjects are presented in Table 1. Most of the septic shock patients had peritonitis or pneumonia, whereas controls had suffered multiple trauma, intracerebral hemorrhage or acute severe bleeding. The SOFA score was significantly higher in the septic group where patients required more norepinephrine and more mechanical ventilation.

Table 1 Demographic and clinical data of septic shock and non-septic patients

\begin{tabular}{|c|c|c|c|}
\hline & Septic shock $(n=20)$ & Control $(n=20)$ & $P$ \\
\hline Age [years (Q1-Q3)] & $68(59.2-76.7)$ & $70.5(54.2-75.5)$ & 0.65 \\
\hline Male $[n(\%)]$ & $17(85)$ & $13(65)$ & 0.14 \\
\hline BMI [kg/m² (Q1-Q3)] & $24.70(20.2-28.6)$ & $25(20.2-30.5)$ & 0.65 \\
\hline Dyslipidemia [n (\%)] & $5(25)$ & $3(15)$ & 0.69 \\
\hline Statin medication [n (\%)] & $3(15)$ & $0(0)$ & 0.23 \\
\hline SAPSII (Q1-Q3) & $39(29-59.5)$ & $38(30-51)$ & 0.73 \\
\hline SOFA score (Q1-Q3) & $8(8-10)$ & $6(4-8)$ & $<0.001$ \\
\hline Mechanical ventilation [n (\%)] & $20(100)$ & $14(70)$ & 0.02 \\
\hline Need for norepinephrine [n (\%)] & $20(100)$ & $11(55)$ & 0.001 \\
\hline Norepinephrine (micg/kg/min) & $0.42(0.31-0.64)$ & $0.12(0.0-0.27)$ & $<0.001$ \\
\hline Enteral nutrition [n (\%)] & $12(60)$ & $18(90)$ & 0.065 \\
\hline Parenteral nutrition [n (\%)] & $5(25)$ & $2(10)$ & 0.41 \\
\hline \multicolumn{4}{|l|}{ Diagnosis at admission [n (\%)] } \\
\hline Peritonitis & $10(50)$ & - & - \\
\hline Pneumonia & $5(25)$ & - & - \\
\hline Cellulitis & $2(10)$ & - & - \\
\hline Arthritis & $1(5)$ & - & - \\
\hline Hepatic abscess & $1(5)$ & - & - \\
\hline Trauma & - & $6(30)$ & - \\
\hline Intracerebral hemorrhage & - & $6(30)$ & - \\
\hline Traumatic brain injury & - & $5(25)$ & - \\
\hline Hemorrhagic shock & - & $2(10)$ & - \\
\hline
\end{tabular}


Except for these parameters, there was no significant difference in baseline characteristics between septic shock cases and controls. In particular, the SAPSII score was not different between the two groups. In order to assess the host response to bacterial exposure, LPS-binding protein (LBP) concentration was measured in plasma. This protein has been used as a potential biomarker reflecting the innate immune response to microbial products. Interestingly, plasma LBP levels were higher in septic versus non-septic cases at day 1 (Table 2). Neutrophil activation by bacterial material may lead to the production of NETs (neutrophil extracellular traps) that can be detected in plasma by measuring cell-free DNA. This marker was also increased under septic conditions at day 1 (Table 2). Finally, patients experiencing a septic shock presented higher cytokine concentrations than control patients, as measured at day 1 ( $\mathrm{Il}-1 \mathrm{~b}=44.4 \mathrm{pg} / \mathrm{ml}(20.6-$ 86 ) versus $16.6 \mathrm{pg} / \mathrm{ml}$ (9.9-29), $p=0.016$; Il-6=3363 pg/ $\mathrm{ml}(1069-13,968)$ versus $317 \mathrm{pg} / \mathrm{ml}(118-604), p<0.001$; $\mathrm{Il}-8=357 \mathrm{pg} / \mathrm{ml}(187-753)$ versus $89 \mathrm{pg} / \mathrm{ml}(62-121)$, $p<0.001$ ) (Additional File 1: Fig. S1).

Concerning outcome, mortality was $15 \%(n=3)$ in the septic group and $10 \%(n=2)$ in the non-septic group at day $7(P=1.0)$. At day 28 , mortality in the septic group patients rose to $25 \%(n=5)$ and $20 \%(n=4)$ in the nonseptic group $(P=1.0)$.

\section{Lipid profile in septic shock cases and controls}

Concentrations of total cholesterol and HDL/LDL-C, but not of triglycerides, were lower in septic shock cases than in controls within $48 \mathrm{~h}$ of admission (Table 3). Case-control differences at $24 \mathrm{~h}$ were similar to those observed at $48 \mathrm{~h}$ for all lipid parameters. The major difference observed between septic and non-septic patients was found for HDL-C that remained significantly different between groups, even at day 7 (whereas septic patients recovered similar LDL-C levels to those of controls). Apolipoprotein A1 concentration was not statistically different at days 2 and 7. Among septic shock cases and controls, we investigated the association of HDL-C with SOFA, SAPSII, LBP and cf-DNA. At day 1, significant negative correlations were observed between HDL-C and cf-DNA $(r=-0.74, P<0.0001)$ and LBP $(r=-0.31$, $P=0.004$ ), but not with SOFA and SAPSII scores (all $P>0.11)$. No correlation was observed between HDL concentration and patient outcome (mortality and length of stay in ICU) in either septic or control patients.

\section{Lipoprint analysis}

A major change in the distribution of HDL particles was observed in septic versus non-septic patients. A statistically significant decrease in small and intermediary fractions, in parallel with an increase in large particles, was observed at $24 \mathrm{~h}$ and at $48 \mathrm{~h}$ in septic versus non-septic patients (Fig. 1). At day 7, septic patients presented similar HDL profiles to those of non-septic subjects (Fig. 1). Thus, in addition to decreased levels of HDL-C, the remaining HDL particles were larger in septic versus non-septic patients. While we described a significant difference in HDL size between septic and non-septic

Table 2 Biological data of septic shock and non-septic patients at day 1, day 2 and day 7

\begin{tabular}{|c|c|c|c|c|c|c|}
\hline & \multicolumn{2}{|l|}{ At day 1} & \multicolumn{2}{|l|}{ At day 2} & \multicolumn{2}{|l|}{ At day 7} \\
\hline & Median or \% (Q1-Q3) & $p$ & Median or \% (Q1-Q3) & $P$ & Median or \% (Q1-Q3) & $p$ \\
\hline \multicolumn{7}{|c|}{ Total serum proteins (g/L) } \\
\hline Non-septic patients & $64.5(55.2-68.7)$ & 0.16 & $60(51-62)$ & 0.01 & $62(56.5-69.7)$ & 0.06 \\
\hline Septic shock & $55(49.5-65.2)$ & & $50.5(45.5-54.2)$ & & $57(51-52.7)$ & \\
\hline \multicolumn{7}{|l|}{ Leukocyte/mm³ } \\
\hline Non-septic patients & $13,460(8400-15,210)$ & 0.53 & $11,270(8630-13,790)$ & 0.09 & $9070(6970-12,200)$ & 0.44 \\
\hline Septic shock & $13,925(9000-20,155)$ & & $13,945(10,048-17,133)$ & & $10,290(7910-15,670)$ & \\
\hline \multicolumn{7}{|l|}{ Neutrophils/mm³ } \\
\hline Non-septic patients & $10,710(6318-13,895)$ & 0.84 & $9640(8605-11,565)$ & 0.41 & $7620(5033-12,833)$ & 0.86 \\
\hline Septic shock & $10,120(6850-18,900)$ & & $12,475(6958-15,788)$ & & $7490(5870-12,425)$ & \\
\hline \multicolumn{7}{|l|}{$\operatorname{LBP}(\mu \mathrm{g} / \mathrm{mL})$} \\
\hline Non-septic patients & $39.3(23.7-47.5)$ & $<0.001$ & $44.3(37.8-49.6)$ & 0.09 & $46.6(28.9-52.5)$ & 0.45 \\
\hline Septic shock & $47.9(45-49.7)$ & & $48.9(44.4-50.9)$ & & $48.8(43.1-51.3)$ & \\
\hline \multicolumn{7}{|l|}{ cf-DNA (ng/mL) } \\
\hline Non-septic patients & $582.1(529.3-694.3)$ & $<0.0001$ & $730.2(571.8-806.5)$ & $<0.0001$ & 866.6 (754.4-958.9) & 0.84 \\
\hline Septic shock & 980.9 (872.4-1323) & & $975.1(841.6-1157)$ & & $835.8(749.3-1023)$ & \\
\hline
\end{tabular}

Continuous variables are expressed as medians (interquartile range), and categorical variables are expressed as frequencies (percentages)

A Mann-Whitney test was used for this analysis 
Table 3 Lipid parameters in septic patients and controls

\begin{tabular}{|c|c|c|c|}
\hline Lipid profile at day 1 & Septic shock $(n=20)$ & Non-septic patients $(n=20)$ & $p$ \\
\hline Total cholesterol, mmol// & $2.1[1.6-2.7]$ & $4.0[3.1-4.8]$ & $<0.0001$ \\
\hline $\mathrm{mg} / \mathrm{dl}$ & 82 [62-105] & 156 [121-187] & \\
\hline LDL-C, mmol/l & $1.0[0.8-1.6]$ & $2.3[1.4-2.9]$ & 0.001 \\
\hline $\mathrm{mg} / \mathrm{dl}$ & $39[31-62]$ & 89 [54-112] & \\
\hline $\mathrm{HDL}-\mathrm{C}(\mathrm{mmol} / \mathrm{l})$ & $0.4[0.3-0.7]$ & $1.3[1.0-1.5]$ & $<0.0001$ \\
\hline $\mathrm{mg} / \mathrm{dl}$ & 15 [12-27] & $50[39-58]$ & \\
\hline Triglycerides, mmol// & $0.9[0.7-1.7]$ & $1.0[0.7-1.2]$ & 0.69 \\
\hline $\mathrm{mg} / \mathrm{dl}$ & 80 [62-150] & $88[62-106]$ & \\
\hline Apolipoprotein-A1, mg/l & 916 [315-2543] & 2482 [1428-5518] & 0.05 \\
\hline Lipid profile at day 2 & Septic shock $(n=18)$ & Non-septic patients $(n=19)$ & $p$ \\
\hline Total cholesterol, mmol// & $1.8[1.2-2.9]$ & $3.2[2.7-3.9]$ & 0.001 \\
\hline $\mathrm{mg} / \mathrm{dl}$ & $70[47-113]$ & 125 [105-152] & \\
\hline LDL-C, mmol/l & $0.9[0.4-1.5]$ & $1.5[1.1-2.2]$ & 0.02 \\
\hline $\mathrm{mg} / \mathrm{dl}$ & $35[15-58]$ & $58[43-86]$ & \\
\hline $\mathrm{HDL}-\mathrm{C}, \mathrm{mmol} / \mathrm{l}$ & $0.3[0.2-0.6]$ & $1.0[0.9-1.4]$ & $<0.0001$ \\
\hline $\mathrm{mg} / \mathrm{dl}$ & $12[8-24]$ & $39[35-54]$ & \\
\hline Triglycerides, mmol// & $1.4[0.9-1.7]$ & $1.0[0.8-1.1]$ & 0.16 \\
\hline $\mathrm{mg} / \mathrm{dl}$ & 124 [80-150] & 88 [71-97] & \\
\hline Apolipoprotein-A1, mg/l & 787 [357-2234] & 1562 [965-3101] & 0.22 \\
\hline Lipid profile at day 7 & Septic shock $(n=15)$ & Non-septic patients $(n=12)$ & $p$ \\
\hline Total cholesterol, mmol// & $2.7[1.7-3.5]$ & $3.4[2.2-3.8]$ & 0.29 \\
\hline $\mathrm{mg} / \mathrm{dl}$ & 105 [66-136] & $132[86-148]$ & \\
\hline LDL-C, mmol/l & $1.5[0.9-2.0]$ & $1.8[1.4-2.5]$ & 0.38 \\
\hline $\mathrm{mg} / \mathrm{dl}$ & $58[35-77]$ & 70 [54-97] & \\
\hline $\mathrm{HDL}-\mathrm{C}, \mathrm{mmol} / \mathrm{l}$ & $0.4[0.3-0.6]$ & $0.7[0.5-1.2]$ & 0.04 \\
\hline $\mathrm{mg} / \mathrm{dl}$ & 15 [12-24] & 27 [19-46] & \\
\hline Triglycerides, mmol/l & $1.3[1.1-1.6]$ & $1.0[0.9-1.5]$ & 0.25 \\
\hline $\mathrm{mg} / \mathrm{dl}$ & 115 [97-142] & 88 [80-133] & \\
\hline Apolipoprotein-A1, mg/l & 1340 [391-1922] & $962[508-3752]$ & 0.98 \\
\hline
\end{tabular}

Results are expressed as medians (IQR). The statistical differences were analyzed by a Mann-Whitney test

patients, we did not find any correlation between HDL size at day 1, 2 or 7 and patient outcome (mortality or length of stay in ICU) in either septic or control patients. Interestingly, there was a significant positive correlation between the percentage of large particles at day 1 and LBP concentration $(r=0.39, p=0.012)$ and a significant negative correlation between percentage of small particles at day 1 and LBP concentration $(r=-0.5, p=0.001)$ (Additional File 2: Fig. S2). No such correlation between particles size and LBP concentration was found at day 2 and 7.

\section{Discussion}

In the present study, we have compared a group of septic shock patients to a control group consisting of patients with a systemic inflammatory response syndrome having suffered traumatic brain injury or multiple traumas, intracerebral hemorrhage or acute severe bleeding. These two groups are comparable in terms of SAPSII. We have shown that at admission to ICU, HDL-C concentrations were lower and HDL particles were larger in septic versus non-septic patients. This point is of interest since small HDLs are usually considered as functional particles; in sepsis, there is not only a shift toward large non-functional HDLs but also a marked decrease in the concentration of these lipoproteins (HDL cholesterol).

We show that LBP, an acute phase protein predominantly synthesized by the liver in response to gram-negative bacteria [26], is significantly higher in septic versus non-septic patients at 24 and $48 \mathrm{~h}$ after admission. The higher cell-free DNA concentration in plasma attested the increased cell death in septic conditions. The release of extracellular DNA is a well-known active phenomenon for neutrophils that are over-stimulated (producing 


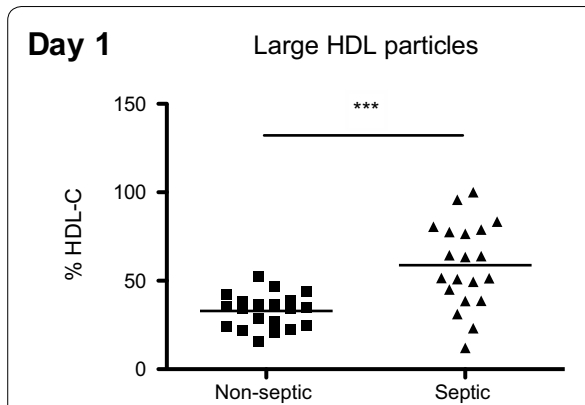

Day 2

Large HDL particles

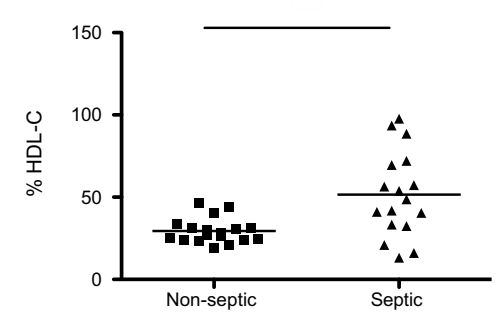

Day 7

Large HDL particles

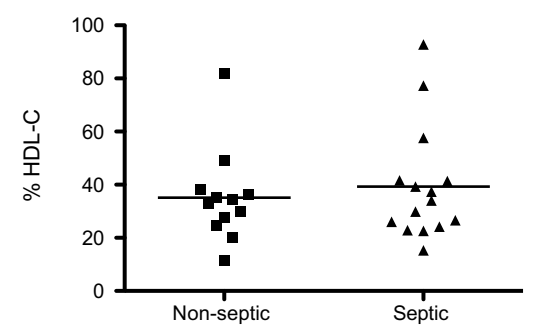

Intermediate HDL particles

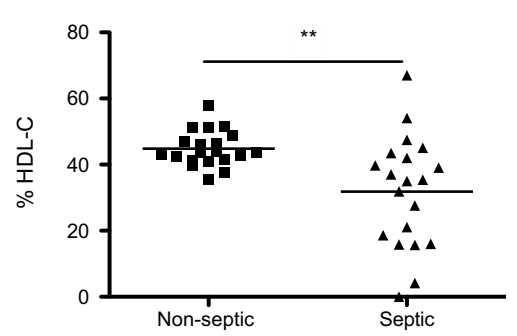

Intermediate HDL particles

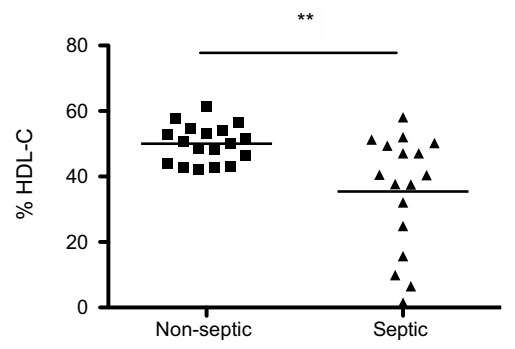

Intermediate HDL particles

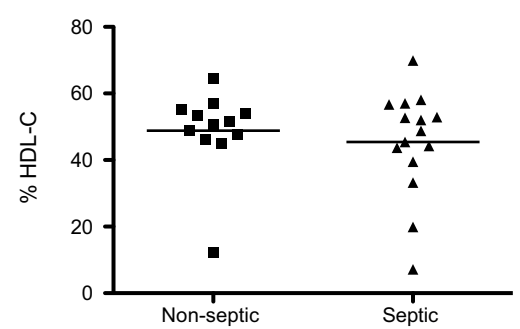

Small HDL particles

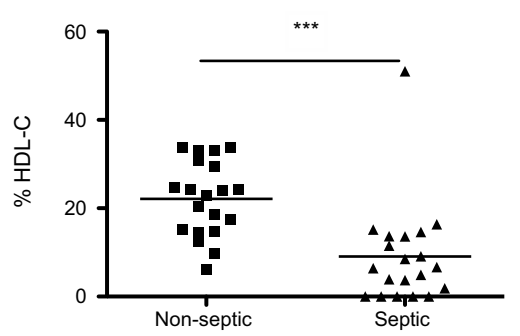

Small HDL particles

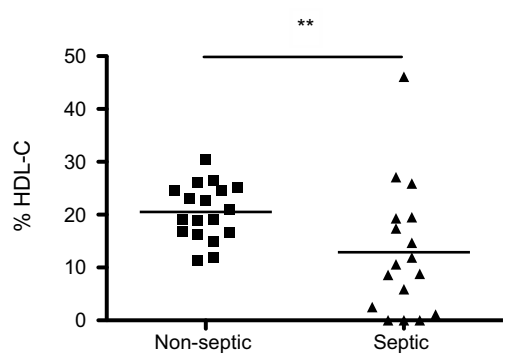

Small HDL particles

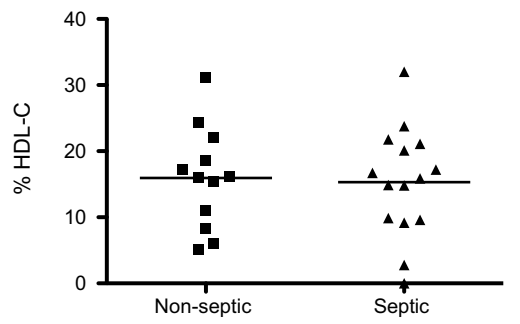

Fig. 1 Lipoprint analysis of HDL particle size. Distribution of the different HDL subfractions (large, intermediate and small) in plasma of septic patients and non-septic patients at day 1, day 2 and day 7. The results are presented as percentages of total cholesterol detected in HDL fractions. ${ }^{*} p<0.05,{ }^{* *} p<0.01,{ }^{* * *} p<0.001$ (Mann-Whitney)

Neutrophil Extracellular Traps, NETs), in particular with LPS [25, 27]. In our conditions, it cannot be excluded that cells other than neutrophils may contribute to the increased cf-DNA concentration in septic patients. Neutrophils isolated from septic patients have been reported to be less prone to release DNA than those from nonseptic subjects; this was paralleled by an increased NET concentration in the septic group [28], suggesting that these cells have already been activated and have subsequently released cf-DNA in plasma.

\section{Lipid profile: HDL particle size in septic versus non-septic and septic patients}

By comparing septic shock patients to control ICU patients of similar severity, we show that the lipid profile is profoundly modified under septic conditions. Whereas both LDL-C and HDL-C were lower in septic patients, triglyceride levels were not significantly different between the two groups, albeit slightly higher in septic patients at days 2 and 7. Numerous studies have reported that the serum lipid profile is modified in septic relative to nonseptic patients (for review, see [29]). These changes were documented more than 30 years ago [30]. In our study, it is unlikely that lipid changes are due to beta-blockers or angiotensin converting enzyme inhibitors since these drugs do not significantly modify HDL levels. Also, no differences in these treatments were observed between groups (data not shown). However, in a recent work by Khera et al., a 12-month rosuvastatin treatment $(20 \mathrm{mg} /$ day) did not change the cholesterol efflux capacity of HDLs, but led to an increase in HDL cholesterol (+7.7\%), apoA-I (+4.3\%), and HDL particle number $(+5.2 \%)$ [31]. In our cohort of patients, no differences were observed regarding statin medication between the two groups. 
To our knowledge, this is the first demonstration that septic shock patients present a shift of HDL size from small to large particles compared to non-septic patients. In accordance with our results, De la Llera-Moya et al. [32] reported that LPS-induced endotoxemia in healthy volunteers led to a depletion of pre-betala and small- and medium-sized HDL particles, determined by 2D eletrophoresis and nuclear magnetic resonance. Interestingly, small HDL particles were shown to be more antioxidant and more anti-inflammatory in cardiovascular disease [33], but large HDL particles as determined by Lipoprint technology appear to be more associated with a reduced risk of coronary artery disease $[17,18]$.

\section{HDLs: therapeutic option or surrogate marker?}

Globally, HDL particles exert a variety of protective effects on endothelial cells [33] that may modulate the physiological response under inflammatory conditions [34]. For example, HDLs have been shown to modulate vascular cell activation [13, 35] and endothelial expression of adhesion molecules [36] that may in turn reduce leukocyte extravasation. In addition, HDLs have been reported to interact with LPS and to facilitate its clearance by different organs [37]. However, different therapeutic strategies aiming at inhibiting LPS binding to TLR4 failed to improve the outcome of severe sepsis patients (no reduction in 28-day and 1-year all-cause mortality) [38]. HDLs, in addition to their LPS-scavenging capacity, may provide a more global endothelial protection and leukocyte pacification that may account for their protective role under inflammatory conditions. Barlage et al. suggested that the beneficial effects of HDLs on gram-positive infections may be due to other anti-inflammatory properties, including the modulation of neutrophil activation [22]. HDLs could also provide a protective effect in sepsis due to their antioxidant capacity. The infusion of reconstituted HDLs (that are considered to be small HDL particles) has been shown to modulate inflammatory parameters in different animal or human settings of endotoxemia [36, 39, 40]. Specifically in rodent models of sepsis, infusion of reconstituted HDLs or mimetic peptides improved survival [36, 41-43].

Moreover, because sepsis still remains an important cause of mortality and morbidity, early biomarkers could be useful to establish a diagnosis of sepsis and also to indicate its severity. To date, there is no biomarker that fulfills these objectives in terms of sensitivity and specificity [4]. The use of HDL concentration, size and/ or functionality may thus represent an early and sensitive biomarker of sepsis, low levels being associated with severity and poor outcome. Interestingly, a recent study has shown that variations in genes involved in HDL metabolism could contribute to changes in HDL-C level; a rare missense variant in CETP (rs1800777-A) was thus associated with significant reductions in HDL-C concentration during sepsis [44]. Carriers of the A allele had an increased mortality and morbidity compared to non-carriers.

\section{Some hypotheses concerning the mechanistic basis of our findings}

- First, the interaction between HDL particles and bacterial components (LPS or LTA) could produce changes in HDL size and potential functions.

- Second, septic conditions and especially a procoagulant state could lead to the aggregation of HDL particles that could participate in increasing HDL size according to the Lipoprint technology.

- Third, sepsis impairs the capacity of HDL to induce cellular cholesterol efflux. ABCA-1 dysfunction could lead a decrease in the synthesis of small pre- $\beta$ HDL. Moreover, the SRB-1 depletion observed in case of inflammatory condition such as sepsis could also participate in increasing the proportion of large HDL-2 and HDL-3 proportion.

- Lastly, the septic condition increases HDL-associated Serum Amyloid A (SAA). HDL size could be impacted by this association.

\section{Our study has several limitations}

- First, this is a monocentric study with a small population size. However, with only 20 patients per group, we have found a significant difference in HDL particle size between the two groups.

- Second, our analysis was performed using only one electrophoresis system (lipoprint). Other techniques such as nuclear magnetic resonance should also be performed.

- Third, more patients received norepinephrine in septic versus the control group. Norepinephrine stimulates the expression of lipoprotein lipase, which exerts an important role in the metabolism of lipids by hydrolyzing triglycerides contained in chylomicrons and VLDL. Its overexpression may participate in lipid profile modifications under septic conditions.

- Lastly, we did not show in this study any mechanistic pathway explaining the shift toward the large size.

\section{Conclusion}

Our study confirms that HDL-C concentration is very low in septic relative to non-septic patients admitted to our ICU and demonstrates for the first time that HDL 
particles are larger under septic conditions. Further studies should be conducted in order to understand the mechanisms of this shift. According to numerous experimental studies [36, 42, 43, 45, 46], HDL supplementation may represent a potential therapy for septic patients. However, additional evidence should be provided in animal models, particularly on hard endpoints such as mortality in order to translate HDL therapy into clinical practice.

\section{Additional files}

Additional file 1: Figure S1. Cytokine concentrations at day 1. II- $1 \mathrm{~b}$, II-6 and II-8 concentrations between septic and non-septic patients at day 1.* $p<0.05,{ }^{* *} p<0.01,{ }^{* * *}: p<0.001$ (Mann-Whitney).

Additional file 2: Figure S2. Correlation between the percentage of large and small HDL particles and LBP concentration at day 1 .

\section{Abbreviations}

AIDS: acquired immune deficiency syndrome; HDL: high-density lipoprotein; ICU: intensive care unit; IL-1 b: interleukin 1 b; IL-6: interleukin 6; IL-8: interleukin 8; LBP: lipopolysaccharide; LDL: low-density lipoprotein; NET: neutrophil extracellular traps; NO: nitric oxide; PAF-AH: platelet-activating factor acetylhydrolase; PON1: paraoxonase; TLR-4: toll-like receptor 4; TNF-alpha: tumor necrosis factor-alpha; SAPS II: simplified acute physiology score II; SAA: serum A amyloid; SOFA: sequential organ failure assessment.

\section{Acknowledgements}

The authors thank Dr Mary Osborne-Pellegrin for help in editing the manuscript.

\section{Authors' contributions}

DD and ST designed the study, performed the experimental work, participated in data acquisition, performed the statistical analysis, the interpretation of the results and drafted the manuscript. OM designed the study, performed the experimental work, participated in data acquisition, performed statistical analysis, interpreted the results, supervised the study and drafted the manuscript. SD, JYS, JP performed the experimental work and participated in the interpretation of the results. CG, NZ, HA, SA, ED participated in data acquisition. JD and PM participated in the study design and the interpretation of the results. All authors have read and approved the final manuscript.

\section{Funding}

This work was supported by European Regional Development Funds RE0001897 (EU-Région Réunion-French State national counterpart).

\section{Availability of data and materials}

The datasets used and analyzed during the current study are available from the corresponding author on reasonable request.

\section{Ethics approval and consent to participate}

This study was approved by our local ethics committee (Comite de Protection des Personnes de I'Université Paris VII no SC 13-026), which waived the need for written informed consent because of the observational nature of the study.

\section{Consent for publication}

Not applicable.

\section{Competing interests}

The authors declare that they have no competing interests.

\section{Author details}

${ }^{1}$ INSERM, UMR 1188 Diabète athérothombose Réunion Océan Indien (DéTROI), Université de La Réunion, 2 Rue Maxime Rivière, 97491 Sainte
Clotilde, La Réunion, France. ${ }^{2}$ AP-HP, Service d'Anesthésie-Réanimation, CHU Bichat-Claude Bernard, 46 Rue Henri Huchard, 75018 Paris, France. ${ }^{3}$ Inserm U1 148, Laboratory for Vascular, Translational Science Bichat Hospital, 46 Rue Henri Huchard, 75018 Paris, France. ${ }^{4}$ AP-HP, Service d'Anesthésie-Réanimation, Hôpitaux Universitaires Paris-Sud, Université Paris-Sud, Hôpital de Bicêtre, 78 Rue du Général Leclerc, 94270 Le Kremlin-Bicêtre, France. ${ }^{5}$ Laboratoire d'étude de la Microcirculation, «Bio-CANVAS: Biomarkers in CardioNeuroVascular DISEASES» UMRS 942, Paris, France. ${ }^{6}$ UMR1 137 IAME, Inserm, Laboratoire de Génétique Moléculaire, Université Paris Diderot and AP-HP, Hôpital Bichat, Paris, France. ${ }^{7}$ Inserm UMR1 152, Physiopathologie et Epidémiologie des Maladies Respiratoires, Paris, France. ${ }^{8}$ CHU de La Réunion, Saint-Denis, France. ${ }^{9}$ INSERM U1 188 Diabète athérothrombose Thérapies Réunion Océan Indien (DéTROI), Université de La Réunion au CYROI, 2, Rue Maxime Rivière, 97490 Sainte Clotilde, La Réunion, France.

Received: 26 February 2019 Accepted: 30 May 2019

Published online: 13 June 2019

\section{References}

1. Rhodes A, Evans LE, Alhazzani W, Levy MM, Antonelli M, Ferrer R, et al. Surviving sepsis campaign: international guidelines for management of sepsis and septic shock: 2016. Crit Care Med. 2017:45(3):486-552.

2. Annane D, Bellissant E, Cavaillon J-M. Septic shock. Lancet Lond Engl. 2005:365(9453):63-78.

3. Singer M, Deutschman CS, Seymour CW, Shankar-Hari M, Annane D, Bauer $\mathrm{M}$, et al. The third international consensus definitions for sepsis and septic shock (sepsis-3). JAMA. 2016;315(8):801-10.

4. Pierrakos C, Vincent J-L. Sepsis biomarkers: a review. Crit Care Lond Engl. 2010;14(1):R15.

5. Angus DC, van der Poll T. Severe sepsis and septic shock. N Engl J Med. 2013;369(21):2063.

6. Hoesel LM, Gao H, Ward PA. New insights into cellular mechanisms during sepsis. Immunol Res. 2006:34(2):133-41.

7. Ait-Oufella H, Maury E, Lehoux S, Guidet B, Offenstadt G. The endothelium: physiological functions and role in microcirculatory failure during severe sepsis. Intensive Care Med. 2010;36(8):1286-98.

8. Nofer JR, Kehrel B, Fobker M, Levkau B, Assmann G, von Eckardstein A. $\mathrm{HDL}$ and arteriosclerosis: beyond reverse cholesterol transport. Atherosclerosis. 2002;161(1):1-16.

9. Cooney MT, Dudina A, De Bacquer D, Wilhelmsen L, Sans S, Menotti A, De Backer G, Jousilahti P, Keil U, Thomsen T, et al. HDL cholesterol protects against cardiovascular disease in both genders, at all ages and at all levels of risk. Atherosclerosis. 2009;206(2):611-6.

10. Mineo C, Shaul PW. HDL stimulation of endothelial nitric oxide synthase: a novel mechanism of HDL action. Trends Cardiovasc Med. 2003;13(6):226-31.

11. Lerch PG, Spycher MO, Doran JE. Reconstituted high density lipoprotein $(\mathrm{rHDL})$ modulates platelet activity in vitro and ex vivo. Thromb Haemost. 1998;80(2):316-20

12. Ulevitch RJ, Johnston AR, Weinstein DB. New function for high density lipoproteins. Isolation and characterization of a bacterial lipopolysaccharide-high density lipoprotein complex formed in rabbit plasma. J Clin Invest. 1981;67(3):827-37.

13. Murch $\mathrm{O}$, Collin M, Hinds CJ, Thiemermann C. Lipoproteins in inflammation and sepsis. I. Basic science. Intensive Care Med. 2007:33(1):13-24.

14. Murphy AJ, Woollard KJ, Suhartoyo A, Stirzaker RA, Shaw J, Sviridov D, et al. Neutrophil activation is attenuated by high-density lipoprotein and apolipoprotein $\mathrm{A}-\mathrm{l}$ in in vitro and in vivo models of inflammation. Arterioscler Thromb Vasc Biol. 2011:31(6):1333-41.

15. Zimmerman GA, Mclntyre TM, Prescott SM, Stafforini DM. The plateletactivating factor signaling system and its regulators in syndromes of inflammation and thrombosis. Crit Care Med. 2002;30(5 Suppl):S294-301.

16. El Harchaoui K, Arsenault BJ, Franssen R, Després J-P, Hovingh GK, Stroes ESG, et al. High-density lipoprotein particle size and concentration and coronary risk. Ann Intern Med. 2009;150(2):84-93.

17. Gao F, Ren Y-J, Shen X-Y, Bian Y-F, Xiao C-S, Li H. Correlation between the high density lipoprotein and its subtypes in coronary heart disease. Cell Physiol Biochem Int J Exp Cell Physiol Biochem Pharmacol. 2016;38(5):1906-14 
18. Li J-J, Zhang Y, Li S, Cui C-J, Zhu C-G, Guo Y-L, et al. Large HDL subfraction but not $\mathrm{HDL}-\mathrm{C}$ is closely linked with risk factors, coronary severity and outcomes in a cohort of nontreated patients with stable coronary artery disease: a prospective observational study. Medicine (Baltimore). 2016;95(4):e2600.

19. van Leeuwen HJ, Heezius EC, Dallinga GM, van Strijp JA, Verhoef J, van Kessel KP. Lipoprotein metabolism in patients with severe sepsis. Crit Care Med. 2003;31(5):1359-66.

20. Tanaka S, Labreuche J, Drumez E, Harrois A, Hamada S, Vigué B, et al. Low $\mathrm{HDL}$ levels in sepsis versus trauma patients in intensive care unit. Ann Intensive Care. 2017;7(1):60.

21. Chenaud C, Merlani PG, Roux-Lombard P, Burger D, Harbarth S, Luyasu S, et al. Low apolipoprotein A-l level at intensive care unit admission and systemic inflammatory response syndrome exacerbation. Crit Care Med. 2004;32(3):632-7.

22. Barlage S, Gnewuch C, Liebisch G, Wolf Z, Audebert FX, Gluck T, Frohlich D, Kramer BK, Rothe G, Schmitz G. Changes in HDL-associated apolipoproteins relate to mortality in human sepsis and correlate to monocyte and platelet activation. Intensive Care Med. 2009;35(11):1877-85.

23. Chien JY, Jerng JS, Yu CJ, Yang PC. Low serum level of high-density lipoprotein cholesterol is a poor prognostic factor for severe sepsis. Crit Care Med. 2005;33(8):1688-93.

24. Grundy SM, Stone NJ, Bailey AL, Beam C, Birtcher KK, Blumenthal RS, et al. AHA/ACC/AACVPR/AAPA/ABC/ACPM/ADA/AGS/APhA/ASPC/NLA/ PCNA guideline on the management of blood cholesterol: a report of the american college of Cardiology/American Heart Association task force on clinical practice guidelines. J Am Coll Cardiol. 2018; https://doi. org/10.1016/j.jacc.2018.11.003.

25. Delbosc S, Alsac J-M, Journe C, Louedec L, Castier Y, Bonnaure-Mallet M, et al. Porphyromonas gingivalis participates in pathogenesis of human abdominal aortic aneurysm by neutrophil activation. Proof of concept in rats. PLoS ONE. 2011;6(4):e18679.

26. Tobias PS, Mathison JC, Ulevitch RJ. A family of lipopolysaccharide binding proteins involved in responses to gram-negative sepsis. J Biol Chem. 1988:263(27):13479-81.

27. Brinkmann V, Zychlinsky A. Beneficial suicide: why neutrophils die to make NETs. Nat Rev Microbiol. 2007;5(8):577-82.

28. Hashiba M, Huq A, Tomino A, Hirakawa A, Hattori T, Miyabe H, et al. Neutrophil extracellular traps in patients with sepsis. J Surg Res. 2015;194(1):248-54

29. Pirillo A, Catapano AL, Norata GD. HDL in infectious diseases and sepsis. Handb Exp Pharmacol. 2015:224:483-508.

30. Alvarez C, Ramos A. Lipids, lipoproteins, and apoproteins in serum during infection. Clin Chem. 1986;32(1 Pt 1):142-5.

31. Khera AV, Everett BM, Caulfield MP, Hantash FM, Wohlgemuth J, Ridker PM, et al. Lipoprotein(a) concentrations, rosuvastatin therapy, and residual vascular risk: an analysis from the JUPITER Trial (Justification for the Use of Statins in Prevention: an Intervention Trial Evaluating Rosuvastatin). Circulation. 2014;129(6):635-42.

32. de la Llera Moya M, McGillicuddy FC, Hinkle CC, Byrne M, Joshi MR, Nguyen $\mathrm{V}$, et al. Inflammation modulates human HDL composition and function in vivo. Atherosclerosis. 2012;222(2):390-4.
33. Tran-Dinh A, Diallo D, Delbosc S, Varela-Perez LM, Dang QB, Lapergue $\mathrm{B}$, et al. HDL and endothelial protection. Br J Pharmacol. 2013;169(3):493-511.

34. Trinder M, Boyd JH, Brunham LR. Molecular regulation of plasma lipid levels during systemic inflammation and sepsis. Curr Opin Lipidol. 2019;30:108.

35. Ma J, Dempsey AA, Stamatiou D, Marshall KW, Liew C-C. Identifying leukocyte gene expression patterns associated with plasma lipid levels in human subjects. Atherosclerosis. 2007;191(1):63-72.

36. McDonald MC, Dhadly P, Cockerill GW, Cuzzocrea S, Mota-Filipe H, Hinds CJ, Miller NE, Thiemermann C. Reconstituted high-density lipoprotein attenuates organ injury and adhesion molecule expression in a rodent model of endotoxic shock. Shock. 2003;20(6):551-7.

37. Freudenberg MA, Bøg-Hansen TC, Back U, Galanos C. Interaction of lipopolysaccharides with plasma high-density lipoprotein in rats. Infect Immun. 1980;28(2):373-80.

38. Opal SM, Laterre P-F, Francois B, LaRosa SP, Angus DC, Mira J-P, et al. Effect of eritoran, an antagonist of MD2-TLR4, on mortality in patients with severe sepsis: the ACCESS randomized trial. JAMA. 2013;309(11):1154-62.

39. Pajkrt D, Doran JE, Koster F, Lerch PG, Arnet B, van der Poll T, et al. Antiinflammatory effects of reconstituted high-density lipoprotein during human endotoxemia. J Exp Med. 1996;184(5):1601-8.

40. Casas AT, Hubsch AP, Doran JE. Effects of reconstituted high-density lipoprotein in persistent gram-negative bacteremia. Am Surg. 1996;62(5):350-5.

41. Zhang X, Wang L, Chen B. Recombinant HDL (Milano) protects endotoxin-challenged rats from multiple organ injury and dysfunction. Biol Chem. 2015;396(1):53-60.

42. Dai L, Datta G, Zhang Z, Gupta H, Patel R, Honavar J, et al. The apolipoprotein A-I mimetic peptide $4 \mathrm{~F}$ prevents defects in vascular function in endotoxemic rats. J Lipid Res. 2010;51(9):2695-705.

43. Gupta H, Dai L, Datta G, Garber DW, Grenett H, Li Y, et al. Inhibition of lipopolysaccharide-induced inflammatory responses by an apolipoprotein Al mimetic peptide. Circ Res. 2005;97(3):236-43.

44. Trinder M, Genga KR, Kong HJ, Blauw LL, Lo C, Li X, et al. Cholesteryl ester transfer protein influences high-density lipoprotein levels and survival in sepsis. Am J Respir Crit Care Med. 2019;199(7):854-62.

45. Datta G, Gupta H, Zhang Z, Mayakonda P, Anantharamaiah GM, White CR. HDL mimetic peptide administration improves left ventricular filling and cardiac output in lipopolysaccharide-treated rats. J Clin Exp Cardiol. 2011;2:172.

46. Moreira RS, Irigoyen M, Sanches TR, Volpini RA, Camara NOS, Malheiros DM, et al. Apolipoprotein A-I mimetic peptide 4F attenuates kidney injury, heart injury, and endothelial dysfunction in sepsis. Am J Physiol Regul Integr Comp Physiol. 2014;307(5):R514-24.

\section{Publisher's Note}

Springer Nature remains neutral with regard to jurisdictional claims in published maps and institutional affiliations.

\section{Submit your manuscript to a SpringerOpen ${ }^{\circ}$ journal and benefit from:}

- Convenient online submission

- Rigorous peer review

- Open access: articles freely available online

- High visibility within the field

Retaining the copyright to your article

Submit your next manuscript at springeropen.com 